Article

\title{
Bioactive Compounds and Antioxidant Capacity of Camarosa and Selva Strawberries (Fragaria $x$ ananassa Duch.)
}

\author{
Franco Van De Velde ${ }^{1,2}$, Anna M. Tarola ${ }^{3}$, Daniel Güemes ${ }^{1}$ and María E. Pirovani ${ }^{1, *}$
}

1 Food Technology Institute, Faculty of Chemical Engineering, National University of Littoral, Santiago del Estero 2829, Santa Fe 3000, Argentina;

E-Mails: fvandevelde@fiq.unl.edu.ar (F.V.D.V.); dguemes@fiq.unl.edu.ar (D.G.)

2 National Council of Scientific and Technical Research (CONICET), Santiago del Estero 2829, Santa Fe 3000, Argentina

3 Department of Management, University of Roma La Sapienza,Via del Castro Laurenziano 9, Rome 00161, Italy; E-Mail: annamaria.tarola@uniroma1.it

* Author to whom correspondence should be addressed; E-Mail: mpirovan@fiq.unl.edu.ar; Tel.: +54-342-457-1141 (ext. 2605); Fax: +54-342-457-1164.

Received: 13 February 2013; in revised form: 4 March 2013 / Accepted: 5 March 2013 /

Published: 25 March 2013

\begin{abstract}
Strawberries represent an important source of bioactive compounds due to their vitamin $\mathrm{C}$ and phenolic compound levels, which present high antioxidant effects, beneficial for the maintenance of consumer's health. Argentina is the second largest strawberry producer in The Common Market of the Southern Cone (MERCOSUR), covering the main export destinations of Argentinian strawberries, i.e., Canada, United States, and European Union. Information about the bioactive compound occurrence and antioxidant capacity of these fruits is scarce or not available. Health related compounds of strawberry cultivars (Camarosa and Selva) from different zones of Argentina were investigated. Vitamin C content was in the same range for both studied cultivars. However, Camarosa strawberries, which are the most cultivated, consumed, and exported berries in Argentina, presented higher total phenolic and anthocyanins content, and consequently better in vitro antioxidant capacity. Moreover, there were differences in the occurrence and concentration in the phenolic compound profiles for both cultivars. Camarosa cultivar presented higher content of anthocyanidins, and Selva showed higher total ellagic acid content. The research shows that Argentina's strawberries are an interesting source of bioactive compounds comparable to those in other parts of the world.
\end{abstract}


Keywords: health potential; Camarosa and Selva strawberries; antioxidant capacity; Vitamin C

\section{Introduction}

Strawberry (Fragaria $x$ ananassa Duch.) is a known non-climacteric fruit of frequent human consumption with an attractive color, flavor and aroma. Strawberry is a relevant source of bioactive compounds due to its high level of vitamin $\mathrm{C}$ and phenolics. These compounds present antioxidant effects, and therefore a consequent beneficial effect on the maintenance of consumer health [1-3]. The main phenolic compounds are anthocyanins which are responsible for the fruit color, with reported concentrations of up to $65 \mathrm{mg} / 100 \mathrm{~g}$ fresh weight (FW) [4]. Like other fruits, strawberries can be consumed "in natura", which is advantageous to consumers since there are no nutritional losses due to processing [1].

Argentina is the second largest strawberry producer in MERCOSUR (The Common Market of the Southern Cone), after Brazil. Coronda in Santa Fe Province $\left(31^{\circ} 58^{\prime} 0^{\prime \prime} \mathrm{S}, 60^{\circ} 55^{\prime} 0^{\prime \prime} \mathrm{W}\right)$ and surroundings are one of the main producing strawberry zones in Argentina. About $60 \%$ of Argentina's strawberries are consumed fresh, while most of the remaining production is processed, generally by individual quick freezing. The main overseas destinations of strawberries from Argentina are Canada, United States, and countries of the European Union [5]. Most of strawberries grown in the central region are of the variety "Camarosa" $(80 \%)$, originating from the University of California, USA. It is a variety with prominent climatological adaptation, exceptional quality and flavor and a good tolerance to diseases. Furthermore, "Selva" variety is also cultivated in the southern regions of Argentina [6].

In order to increase the limited knowledge of Argentina's strawberries, the aim of this study was to identify and quantify the bioactive compounds and the in vitro antioxidant capacity of strawberry cultivars from different regions: Camarosa from the central and, Selva from the southern region.

\section{Experimental Section}

\subsection{Plant Material}

Cultivated strawberries (Fragaria x ananassa Duch.) of variety Camarosa were obtained from one planting at Arroyo Leyes $\left(31^{\circ} 27^{\prime} 0^{\prime \prime} \mathrm{S}, 60^{\circ} 40^{\prime} 0^{\prime \prime} \mathrm{W}\right.$ ) (Santa Fe, Argentina) during November 2009, December 2010 and November 2011. Fully developed strawberries were harvested by skilled workers at full ripe stage ( $90 \%$ of the surface showing a red color). They were transported $40 \mathrm{~km}$ directly from the field to the laboratory in Santa Fe. Strawberries (Fragaria x ananassa Duch.) of variety Selva

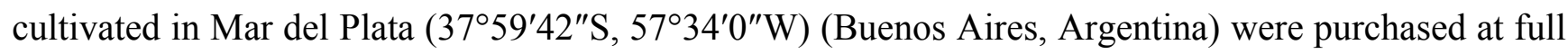
ripe stage (90\% surface red color) in a local market in Santa Fe, Argentina, during March 2010 and March 2011.

Physicochemical characteristics of both strawberries cultivars were: $6.6^{\circ}-8.5^{\circ}$ Brix (soluble solids), $\mathrm{pH} 3.4$, and total acidity: $0.8 \mathrm{mg}$ citric acid/100 g fresh weight (FW). 


\subsection{Strawberry Sample Preparation}

From each lot of Camarosa and Selva strawberry received at the laboratory, $500 \mathrm{~g}$ were randomly sampled. Calyxes and peduncles were removed, and then fruits were washed with tap water, drained on absorbent paper and stored at $-80{ }^{\circ} \mathrm{C}$ until analysis. For phenolic profile determination a portion of each strawberry cultivar was lyophilized and stored at $-80{ }^{\circ} \mathrm{C}$. The moisture was measured for strawberries by drying at $70{ }^{\circ} \mathrm{C}$ until constant weight, according to Deutsch (1995) [7].

\subsection{Apparatus and Software}

LC-UV vitamin C analysis was performed on a KONIK KNK-500-A Series liquid chromatograph, coupled to a variable wavelength detector (UVIS 200 Konik Instruments, Barcelona, Spain). LC-DAD phenolic compounds analysis was performed on a Shimadzu HPLC system, a LC-10AT liquid chromatograph equipped with four pumps FCV-10AL, a degasser DGU-14A, and a photodiode array detector SPD-M20A operating at wavelengths between 200 and $900 \mathrm{~nm}$. LC-DAD data was processed using Shimadzu LC solution software (Shimadzu Co., Kyoto, Japan). Spectrophotometric determinations were performed with a Genesis 5 spectrophotometer with $1 \mathrm{~cm}$ path length cuvettes (Milton Roy, Ivyland, PA, USA). The statistical analysis of data was performed with STATGRAPHICS Centurion XV 15.2.06 (Statpoint Technologies, Inc., Warrenton, VA, USA).

\subsection{Chemicals and Reagents}

Flavonoids (catechin, epicatechin, rutin, quercetin, kaempferol, cyanidin and pelargonidin), and phenolic acids (gallic, ferulic, coumaric and ellagic acid), DL-dithiothreitol (DTT), Folin-Ciocalteu reagent, 1,1-diphenil-2-picrylhydrazil radical (DPPH*), and 2,4,6-tripyridy-s-triazine (TPTZ) were from Sigma Chemical Co. (St. Louis, MO, USA). Metaphosphoric acid was obtained from Merck KGaA (Damnstadt, Germany). Other used chemicals and solvents were pro-analysis and were acquired from Laboratorios Cicarelli (Reagents S.A., San Lorenzo, Santa Fe, Argentina). Distilled water was purified using a Milli-Q system (Millipore, Bedford, MA, USA).

\subsection{Ascorbic Acid and Vitamin C Content}

The ascorbic acid (AA) and vitamin $\mathrm{C}$ (VitC) content were determined by HPLC according to van de Velde et al. [8]. Separations were achieved in a reversed phase column Phenomenex Gemini $5 \mu \mathrm{m} \mathrm{C18} \mathrm{110A} \mathrm{attached} \mathrm{to} \mathrm{a} \mathrm{Phenomenex} \mathrm{guardcolumn} \mathrm{(Phenomenex} \mathrm{Inc.,} \mathrm{Torrance,} \mathrm{CA,} \mathrm{USA)} \mathrm{at}$ $25{ }^{\circ} \mathrm{C}$. The mobile phase, under isocratic conditions, consisted of a $0.03 \mathrm{~mol} / \mathrm{L}$ sodium acetate/acetic acid buffer, 5\% HPLC-grade methanol $(\mathrm{pH}=5.8)$. The flow rate was $1.15 \mathrm{~mL} / \mathrm{min}$ and the detection was performed at $251 \mathrm{~nm}$. For extraction, samples of $5 \mathrm{~g}$ homogenized strawberries were added to $25 \mathrm{~mL}$ metaphosphoric acid $(30 \mathrm{~g} / \mathrm{L})$, acetic acid $(80 \mathrm{~g} / \mathrm{L})$. The mixture was homogenized for $1 \mathrm{~min}$, sonicated in an ultrasonic bath for $15 \mathrm{~min}$ and then centrifuged at $12,000 \times \mathrm{g}$ at $4{ }^{\circ} \mathrm{C}$ for $20 \mathrm{~min}$. The supernatant was separated and $1 \mathrm{~mL}$ of it was diluted with mobile phase to achieve a final volume of $6 \mathrm{~mL}$, then filtered through a $0.45 \mu \mathrm{m}$ Millipore membrane and injected in the HPLC system for quantifying the content of ascorbic acid (AA) of the samples. For vitamin $\mathrm{C}$ quantification, $1 \mathrm{~mL}$ supernatant was added with $0.2 \mathrm{~mL}$ of DL-dithiothreitol solution $(5 \mathrm{~g} / \mathrm{L}$ DTT prepared in 
$2.6 \mathrm{~mol} / \mathrm{L}$ potassium phosphate dibasic). The mixture was kept in the darkness at $25^{\circ} \mathrm{C}$ for $2 \mathrm{~h}$. Then it was made-up to volume with mobile phase to achieve a final volume of $6 \mathrm{~mL}$, filtered through a $0.45 \mu \mathrm{m}$ Millipore membrane and injected into the HPLC system. Samples were prepared in triplicates. Quantification was performed with ascorbic acid and vitamin $\mathrm{C}$ calibration curves and the results were expressed as mg AA or VitC/100 g FW. Dehydroascorbic acid (DHAA) content was obtained as the difference between vitamin $\mathrm{C}$ and ascorbic acid content.

\subsection{Phenolic Compounds by HPLC}

Phenolic compounds determination was performed by HPLC according to Tarola et al. [9]. The extraction was performed with $0.25 \mathrm{~g}$ lyophilized strawberry samples (dry weight 8.8 and $10.4 \mathrm{~g} / 100 \mathrm{~g} \mathrm{FW}$ in Camarosa and Selva cultivars, respectively) in $5 \mathrm{~mL}$ of HPLC-grade methanol. The extracts were crushed and sonicated for $15 \mathrm{~min}$, then were centrifuged $\left(2500 \times g\right.$ at $25{ }^{\circ} \mathrm{C}$ for $20 \mathrm{~min}$ ) and supernatants were collected. The insoluble plant material was re-extracted twice with $5 \mathrm{~mL}$ HPLC-grade methanol. Collected fractions were concentrated by a nitrogen flow at $25{ }^{\circ} \mathrm{C}$ to $5 \mathrm{~mL}$ and finally filtered through a Millipore $0.45 \mu \mathrm{m}$ pore size filter. These fractions were used for the analysis of free aglycones or nonconjugated or noncondensed phenolic compounds naturally present in strawberry extracts. After taking these samples, an acid hydrolysis was performed over all obtained extracts with the objective of releasing the aglycone portion from glycosylated phenolic compounds and hydrolyzing the conjugated and condensed ones. The hydrolysis consisted in $2 \mathrm{~mL}$ extracted sample plus $1 \mathrm{~mL} \mathrm{HCl} 12 \mathrm{~N}$ at $90{ }^{\circ} \mathrm{C}$ for $50 \mathrm{~min}$. After hydrolysis, the extracts were allowed to cool and were ready to be injected in the HPLC system. Compounds were separated on a $150 \mathrm{~mm} \times$ $4.5 \mathrm{~mm}, 5 \mu \mathrm{m}$ particle size, Supelcosil LC-ABZ column (Sigma-Aldrich Co. LLC, St. Louis, MO, USA) and an Alltech C18 $5 \mu \mathrm{m}$ guard column (Alltech Associates Inc., Deerfield, IL, USA). The mobile phase was a gradient prepared from formic acid in water $(2 \%, \mathrm{pH} 3$, solvent $\mathrm{A})$ and formic acid in methanol ( $2 \%, \mathrm{pH} \mathrm{3}$, solvent $\mathrm{B}$ ): $0.01-8.00 \mathrm{~min}, 15 \% \mathrm{~B}$ isocratic; $8.01-25.00 \mathrm{~min}, 15 \%-50 \% \mathrm{~B}$; 25.01-40.00 $\mathrm{min}, 50 \% \mathrm{~B}$ isocratic; $40.01-50.00 \mathrm{~min}, 50 \%-90 \% \mathrm{~B} ; 50.01-60.00 \mathrm{~min}, 90 \%-15 \% \mathrm{~B}$. Ten minutes of equilibration was required before the next injection. The flow rate was $0.7 \mathrm{~mL} / \mathrm{min}$ at $25^{\circ} \mathrm{C}$. The detector was set at 280,320,360, and $520 \mathrm{~nm}$ and peak identification was performed by comparison the retention times and diode array spectral characteristics with external standards and peak spiking. The quantification was performed through external standard calibration curves for catechin, epicatechin, gallic, ferulic, coumaric and ellagic acids, rutin, quercetin, kaempferol, pelargonidin, and cyanidin. Results were expressed as mg/100 g FW.

\subsection{Antioxidant Capacity, Total Anthocyanins and Total Phenolics Content}

\subsubsection{Extracts Preparation}

For extraction, $5 \mathrm{~g}$ homogenized strawberries were added to $75 \mathrm{~mL}$ acetone/water (80:20) and sonicated for $15 \mathrm{~min}$. The mixture was centrifuged at $12,000 \times \mathrm{g}$ at $4{ }^{\circ} \mathrm{C}$ for $20 \mathrm{~min}$ and then supernatant was separated and used for analysis. 


\subsubsection{Total Anthocyanins Content}

The total anthocyanins (TA) content was determined by the $\mathrm{pH}$ differential method according to Jin-Heo and Yong-Lee [10]. Each sample supernatant $\mathrm{pH}$ was adjusted to 1.0 with a $0.1 \mathrm{~mol} / \mathrm{L} \mathrm{HCl}$ and $25 \mathrm{mmol} / \mathrm{L} \mathrm{KCl}$ solutions; and at $\mathrm{pH} 4.5$ with a $0.4 \mathrm{~mol} / \mathrm{L}$ sodium acetate/acetic acid buffer solution (triplicates). Absorbance readings were measured at 510 and $700 \mathrm{~nm}$. Results were converted to mg pelargonidin-3-glucoside $/ 100 \mathrm{~g} \mathrm{FW}$, using a molar extinction coefficient of $22,400 \mathrm{~L} / \mathrm{mol} \cdot \mathrm{cm}$, a molecular weight of $433.2 \mathrm{~g} / \mathrm{mol}$, an optical path of $1 \mathrm{~cm}$ and an absorbance (A) of:

$$
\mathrm{A}=\left[\left(\mathrm{A}_{510}-\mathrm{A}_{700}\right)_{\mathrm{pH} 1}-\left(\mathrm{A}_{510}-\mathrm{A}_{700}\right)_{\mathrm{pH} 4.5}\right]
$$

Where $\mathrm{A}_{510}$ and $\mathrm{A}_{700}$ are the absorbance measures of samples at $\mathrm{pH} 1.0$ and 4.5.

\subsubsection{Total Phenolics Content}

The total phenolics (TP) content was determined using the Folin-Ciocalteu reagent [11]. Aliquots of $0.125 \mathrm{~mL}$ extracts were added with $0.25 \mathrm{~mL}$ of Folin-Ciocalteu reagent, $0.5 \mathrm{~mL}$ of $\mathrm{Na}_{2} \mathrm{CO}_{3}(20 \%)$ and $4.1 \mathrm{~mL}$ of distilled water. The mixture was incubated for $25 \mathrm{~min}$ at room temperature and then was centrifuged for $5 \mathrm{~min}$ at $2000 \times \mathrm{g}$. Absorbance was measured at $760 \mathrm{~nm}$. Reagent blanks were prepared by replacing the sample volume by acetone/water (80:20). The total phenols content was performed by triplicates. Gallic acid was used as standard and results were expressed as mg gallic acid equivalents per $100 \mathrm{~g} \mathrm{FW}$.

\subsubsection{Antioxidant Capacity by $\mathrm{DPPH}^{*}$}

Antioxidant capacity was estimated by determining of the free-radical scavenging capacity evaluated with the stable radical DPPH*, according to Sánchez-Moreno et al. [12]. For this purpose, extract aliquots $(0.025-0.075 \mathrm{~mL})$ were mixed with $3.9 \mathrm{~mL}$ of a methanol DPPH* solution $(0.03 \mathrm{~g} / \mathrm{L})$. Homogenate solutions were kept in darkness for $120 \mathrm{~min}$, and absorbance was measured at $517 \mathrm{~nm}$. Blanks were included replacing strawberry extracts volumes for acetone/water. The percentage of $\mathrm{DPPH}^{*}$ remaining against extract concentration $(\mathrm{mg} / \mathrm{mL})$ was then plotted to obtain the amount necessary to decrease the initial $\mathrm{DPPH}^{*}$ concentration by $50 \%\left(\mathrm{IC}_{50(\text { sample })}\right)$. The antioxidant activity of strawberry extracts were expressed as the ascorbic acid equivalent antioxidant capacity (AEAC) as mg AA/100 g FW [13]:

$$
\mathrm{AEAC}=\mathrm{IC}_{50(\mathrm{AA})} / \mathrm{IC}_{50 \text { (sample) }} \times 10^{5}
$$

$\mathrm{IC}_{50 \text { (AA) }}$ was determined with an ascorbic acid calibration curve and its value was $3.22 \times 10^{-3} \mathrm{mg} / \mathrm{mL}$.

\subsubsection{Antioxidant Capacity by FRAP}

Antioxidant capacity was determined by means of the ferric reducing antioxidant power (FRAP) technique [14]. The FRAP was obtained by measuring the absorbance change at $593 \mathrm{~nm}$ caused by the reduction of the $\mathrm{Fe}^{3+}$-TPTZ complex to the ferrous form at $\mathrm{pH}$ 3.6. The FRAP reagent was freshly prepared by mixing $25 \mathrm{~mL}$ of acetate buffer $(300 \mathrm{mmol} / \mathrm{L}, \mathrm{pH} 3.6), 2.5 \mathrm{~mL}$ of $\mathrm{FeCl}_{3} \cdot 6 \mathrm{H}_{2} \mathrm{O}$ solution (20 mmol/L). Briefly, $90 \mu \mathrm{L}$ extract was added with $90 \mu \mathrm{L}$ distilled water and $900 \mu \mathrm{L}$ FRAP reagent. 
The homogenate was incubated at $37{ }^{\circ} \mathrm{C}$ for $60 \mathrm{~min}$, and absorbance was measured. Blanks were included replacing strawberry extracts volumes for acetone/water. Results were expressed as mmol $\mathrm{Fe}^{2+} / 100 \mathrm{~g} \mathrm{FW}$, using a $\mathrm{FeSO}_{4} \cdot 7 \mathrm{H}_{2} \mathrm{O}$ calibration curve.

\section{Results and Discussion}

\subsection{Vitamin C Content}

Vitamin C content ranged from 41.2 to $47.6 \mathrm{mg} / 100 \mathrm{~g} \mathrm{FW}$ in Camarosa cultivar and from 28.7 to $51.0 \mathrm{mg} / 100 \mathrm{~g} \mathrm{FW}$ in Selva cultivar. Mean values are presented in Table 1. The natural difference in the vitamin $\mathrm{C}$ content among strawberry cultivars was observed in previous works. A high variability in the vitamin $C$ content was observed by Tulipani et al. [15] among strawberry cultivars from Italy ranging from 23 to $47 \mathrm{mg} / 100 \mathrm{~g} \mathrm{FW}$. Pincemail et al. [16] also describe variability among cultivars from Belgium (ranging from 33.5 to $115.7 \mathrm{mg} / 100 \mathrm{~g} \mathrm{FW}$ ) [7]. Vitamin C content could also vary with growing and storage conditions [17]. Ascorbic acid is the main biologically active form of vitamin C, being reversible oxidized to dehydroascorbic acid, which also exhibits biological capacity. Further oxidation generates diketogulonic acid, which has no biological function and the reaction is no longer reversible [17]. The dehydroascorbic acid content in Camarosa was lower than in Selva cultivar (Table 1). The higher percentage of DHAA in Selva cultivar (33.1\% vs. 11.7\% for Camarosa cultivar) could be due to the postharvest storage.

Table 1. Vitamin C (Vit C), ascorbic acid (AA), dehydroascorbic acid (DHAA), total phenolics (TP), total anthocyanins (TA), and in vitro antioxidant capacity (DPPH* and FRAP) in two strawberry cultivars

\begin{tabular}{ccc}
\hline & \multicolumn{2}{c}{ Cultivar } \\
\cline { 2 - 3 } & \multicolumn{1}{c}{ Camarosa } & Selva \\
\hline Bioactive compounds & & \\
Vit C & $44.5 \pm 3.2^{\mathrm{a}}$ & $39.9 \pm 15.8^{\mathrm{a}}$ \\
AA & $40.2 \pm 3.7^{\mathrm{a}}$ & $27.5 \pm 18.0^{\mathrm{a}}$ \\
DHAA & $5.2 \pm 3.7^{\mathrm{a}}$ & $13.2 \pm 1.6^{\mathrm{b}}$ \\
TP & $295.3 \pm 39.7^{\mathrm{b}}$ & $248.4 \pm 62.3^{\mathrm{a}}$ \\
TA & $38.4 \pm 10.2^{\mathrm{b}}$ & $22.1 \pm 4.2^{\mathrm{a}}$ \\
Antioxidant capacity & \\
DPPH* (AEAC) $^{*}$ & $440.1 \pm 8.1^{\mathrm{b}}$ & $395.7 \pm 7.2^{\mathrm{a}}$ \\
FRAP & $2.4 \pm 0.5^{\mathrm{b}}$ & $1.9 \pm 0.9^{\mathrm{a}}$ \\
\hline
\end{tabular}

Vit C, AA, DHAA: mg AA/100 g FW; TP: mg gallic acid equivalents/100 g FW; TA: mg pelargonidin-3glucoside/100 g FW; DPPH* (AEAC): ascorbic acid equivalent antioxidant capacity, mg AA/100 g FW; FRAP, $\mathrm{mmol} \mathrm{Fe}^{2+} / 100 \mathrm{~g} \mathrm{FW}$; Mean \pm S.D., $n=9$; Values in the same row with different superscript lowercase letters are significantly different $(p \leq 0.05)$ by $t$-test. 


\subsection{Phenolic Compounds Content}

The total phenolic (TP) content and the total anthocyanin (TA) content of Camarosa and Selva strawberries are shown in Table 1. Total phenolic content (ranged from 250.0 to $324.2 \mathrm{mg} / 100 \mathrm{~g} \mathrm{FW}$ ) and total anthocyanin content (ranged from 27.1 to $47.0 \mathrm{mg} / 100 \mathrm{~g} \mathrm{FW}$ ) of Camarosa strawberries were higher than the values observed in Selva strawberries (TP ranged from 205.3 to $292.4 \mathrm{mg} / 100 \mathrm{~g} \mathrm{FW}$ and TA ranged from 19.0 to $25.1 \mathrm{mg} / 100 \mathrm{~g} \mathrm{FW}$ ). Like vitamin $\mathrm{C}$, the phenolic content in strawberries is also dependent on the cultivar and the ripening degree [1].

The HPLC phenolic compounds profiles for both strawberry cultivars are shown in Table 2. Figures 1 and 2 illustrate a typical chromatogram at $280 \mathrm{~nm}$ before and after hydrolysis for Camarosa and Selva strawberries. As explained in Section 2.6, phenolic compounds obtained before acid hydrolysis represent free aglycones or nonconjugated or noncondensed phenolic compounds naturally present in the strawberry extracts. On the other hand, the phenolic compounds obtained after acid hydrolysis represent total aglycones from glycosylated phenolics or conjugated or condensed phenolic compounds in the strawberry extracts.

Table 2. Phenolic compounds concentration before and after acid hydrolysis in two strawberry cultivars.

\begin{tabular}{|c|c|c|c|c|}
\hline \multirow{2}{*}{ Phenolic compound } & \multicolumn{2}{|c|}{ Concentration before acid hydrolysis } & \multicolumn{2}{|c|}{ Concentration after acid hydrolysis } \\
\hline & Camarosa & Selva & Camarosa & Selva \\
\hline Gallic acid & $1.36 \pm 0.05$ & - & $14.28 \pm 1.35^{\mathrm{a}}$ & $17.21 \pm 1.30^{b}$ \\
\hline Catechin & $1.70 \pm 0.17^{\mathrm{a}}$ & $3.35 \pm 0.42^{b}$ & $0.48 \pm 0.09^{\mathrm{a}}$ & $0.67 \pm 0.10^{\mathrm{a}}$ \\
\hline Epicatechin & - & - & $4.02 \pm 0.28^{b}$ & $0.84 \pm 0.20^{\mathrm{a}}$ \\
\hline Ferulic acid & - & - & $3.44 \pm 0.32^{b}$ & $2.75 \pm 0.41^{\mathrm{a}}$ \\
\hline Coumaric acid & - & - & $1.69 \pm 0.20^{\mathrm{a}}$ & $1.96 \pm 0.18^{a}$ \\
\hline Cyanidin & - & - & $4.46 \pm 0.23^{\mathrm{a}}$ & $5.28 \pm 0.29^{b}$ \\
\hline Pelargonidin & - & - & $25.20 \pm 1.11^{\mathrm{b}}$ & $18.67 \pm 1.09^{\mathrm{a}}$ \\
\hline Rutin & $1.0 \pm 0.10^{\mathrm{a}}$ & $1.84 \pm 0.17^{\mathrm{b}}$ & $0.09 \pm 0.01^{\mathrm{a}}$ & $0.10 \pm 0.02^{\mathrm{a}}$ \\
\hline Ellagic acid & $0.61 \pm 0.09^{\mathrm{a}}$ & $0.65 \pm 0.07^{\mathrm{a}}$ & $6.67 \pm 0.46^{\mathrm{a}}$ & $11.87 \pm 2.00^{b}$ \\
\hline Quercetin & - & - & $0.36 \pm 0.09^{b}$ & $0.18 \pm 0.04^{\mathrm{a}}$ \\
\hline Kaempferol & - & - & $0.09 \pm 0.02^{\mathrm{a}}$ & $0.62 \pm 0.09^{b}$ \\
\hline Total phenolics ${ }^{1}$ & $4.66 \pm 0.30^{\mathrm{a}}$ & $5.82 \pm 0.60^{b}$ & $60.79 \pm 1.90^{\mathrm{a}}$ & $60.20 \pm 2.40^{\mathrm{a}}$ \\
\hline
\end{tabular}

Mean \pm S.D., $n=9$; Results expressed as mg/100 g FW; ${ }^{1}$ Sum of the phenolic compound contents; -, Not detected; Different superscript lowercase letters indicate significant differences between strawberry cultivars $(p \leq 0.05)$ by $t$-test. 
Figure 1. HPLC-DAD chromatograms of a Camarosa strawberry extract before (a) and after (b) acid hydrolysis $\left(4 \mathrm{~mol} / \mathrm{L} \mathrm{HCl}, 50 \mathrm{~min}\right.$ at $\left.90{ }^{\circ} \mathrm{C}\right)$ at $280 \mathrm{~nm}$. Peak identification: 1, gallic acid; 2, $( \pm$ )-catechin; 3, (-)-epicatechin; 4, ferulic acid; 5, $p$-coumaric acid; 6 , cyanidin; 7, pelargonidin; 8, rutin; 9, ellagic acid; 10, quercetin; 11, kaempferol.

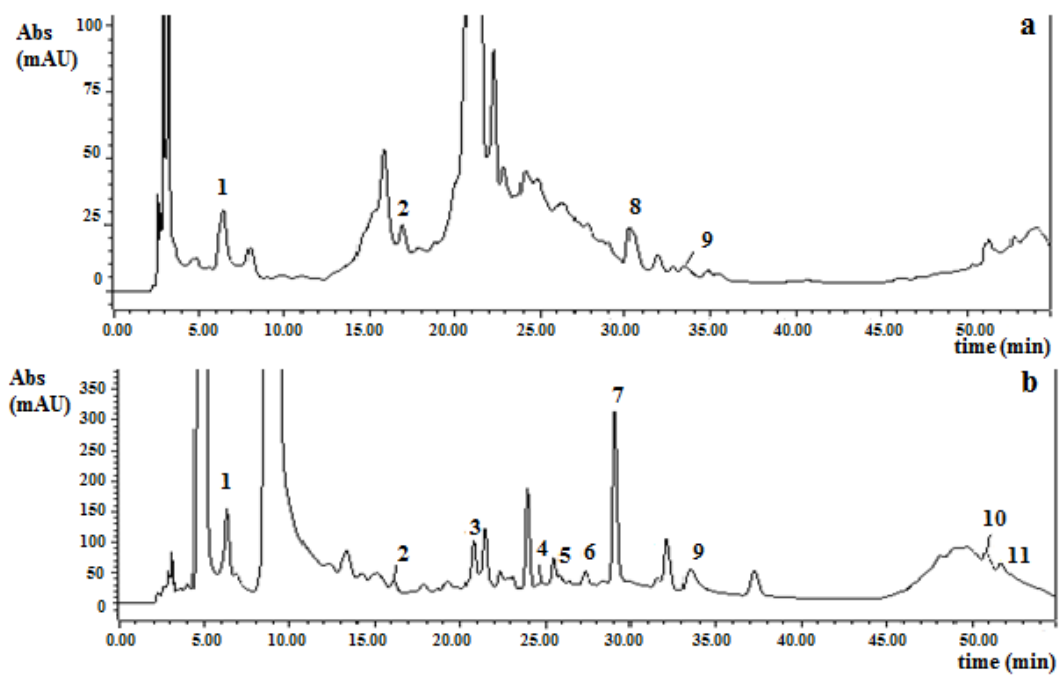

Figure 2. HPLC-DAD chromatograms of a Selva strawberry extract before (a) and after (b) acid hydrolysis ( $4 \mathrm{~mol} / \mathrm{L} \mathrm{HCl}, 50 \mathrm{~min}$ at $\left.90{ }^{\circ} \mathrm{C}\right)$ at $280 \mathrm{~nm}$. Peak identification: 1, gallic acid; 2, $( \pm$-catechin; 3, (-)-epicatechin; 4, ferulic acid; 5, $p$-coumaric acid; 6 , cyanidin; 7, pelargonidin; 8, rutin; 9, ellagic acid; 10, quercetin; 11, kaempferol.
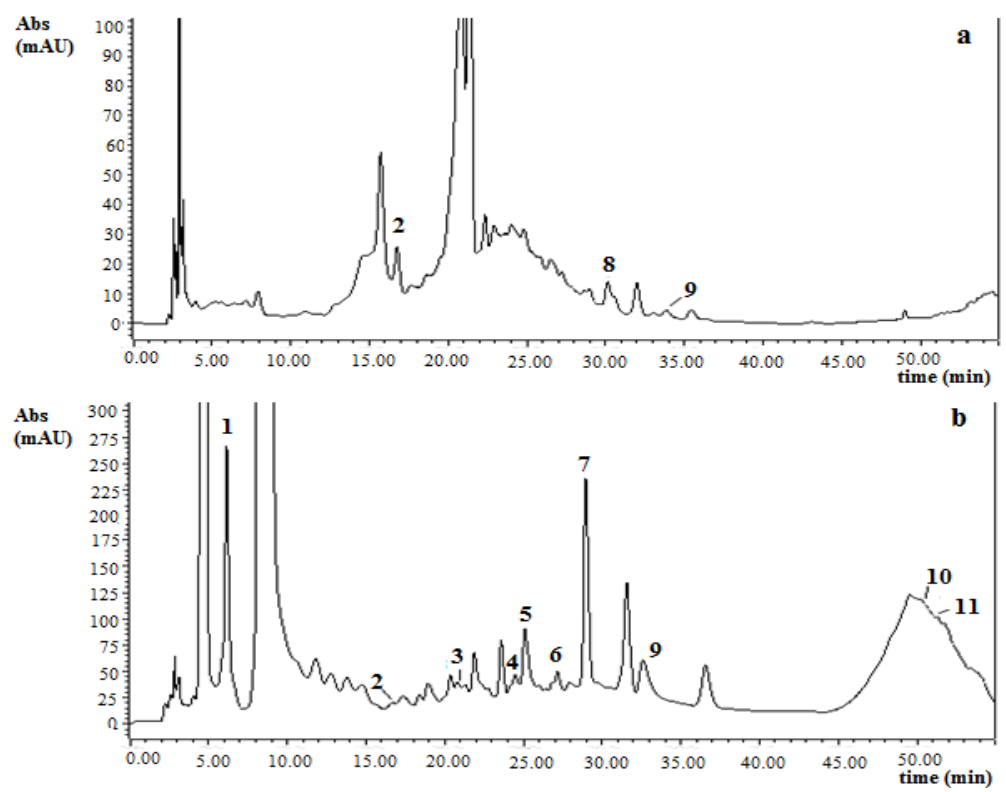

For Camarosa cultivar, gallic acid, catechin, rutin, and ellagic acid were the phenolic compounds found before acid hydrolysis (Table 2). For Selva cultivar, higher catechin and rutin contents were determined but gallic acid was not detected prior to hydrolysis.

Phenolics compounds which were detected and quantified in the nonhydrolyzed strawberry extracts were lower than the content obtained after subsequent hydrolysis (Table 2). In contrast, catechin was affected by hydrolysis conditions and the content was lower in the hydrolyzed extracts. 
The remaining percentage of rutin in the hydrolyzed samples was used as a measure of the hydrolysis efficiency [9]. It was defined as the rutin concentration before acid hydrolysis minus the concentration after acid hydrolysis, divided by the concentration before acid hydrolysis. The hydrolysis efficiencies (\%) were $91 \%$ for Camarosa and $94.5 \%$ for Selva strawberries. These results point out efficient hydrolysis in both strawberry extracts.

Flavonols (quercetin and kaempferol) were found at low concentrations in the hydrolyzed strawberry extracts (Table 2). Although quercetin content was higher in Camarosa strawberries, kaempferol content was found at a lower level in this cultivar. Häkkinen and Törrönen [18] reported that quercetin ranged from 0.3 to $0.4 \mathrm{mg} / 100 \mathrm{~g} \mathrm{FW}$; and kaempferol ranged from 0.6 to $0.9 \mathrm{mg} / 100 \mathrm{~g} \mathrm{FW}$ ) for different strawberry cultivars from Poland and Finland.

Concerning hydroxycinnamic acid derivatives (ferulic and coumaric acid), coumaric acid content (Table 2) was similar for both strawberry cultivars $(p>0.05)$ and was in a similar range as reported by Häkkinen and Törrönen [18] ranging from 0.7 to $1.8 \mathrm{mg} / 100 \mathrm{~g} \mathrm{FW}$ in strawberries from Finland and Poland; and Mattila et al. [19] who reported a mean value of $2.6 \mathrm{mg} / 100 \mathrm{~g} \mathrm{FW}$ in strawberries from Finland. However, ferulic acid was not reported from strawberries in these studies. In our case, ferulic acid content was $20 \%$ higher in Camarosa than Selva strawberries (Table 2).

Free ellagic acid levels (before samples hydrolysis) are generally low, although substantial quantities of this compound can be detected after acid hydrolysis of extracts, as a result of ellagitannin breakdown [2,20]. The free ellagic acid concentrations (Table 2) were similar for both studied strawberry cultivars $(p>0.05)$, and were in agreement with those reported for seven Brazilian strawberries ( 0.6 to $2.6 \mathrm{mg} / 100 \mathrm{~g} \mathrm{FW})$ by da Silva Pindo et al. [2]. Total ellagic acid content (hydrolyzed samples) was higher in Selva than in Camarosa strawberries (Table 2). The content of total ellagic acid in Camarosa was in agreement with the data reported by Williner et al. [21] for the same strawberry variety from Coronda, Argentina (mean value: $6.16 \mathrm{mg} / 100 \mathrm{~g} \mathrm{FW}$ ). Moreover, total ellagic content in both strawberry cultivars was slightly lower than those reported by da Silva Pinto et al. [2] ranging from 17 to $47 \mathrm{mg} / 100 \mathrm{~g} \mathrm{FW}$.

Anthocyanidins content can be considered as an approximate amount of the anthocyanins content (anthocyanidins in their glycoside form). In this sense, the main anthocyanins found in strawberries are pelargonidin-3-glucoside, and pelargonidin-3-rutinoside and cyanidin-3-glucoside present as minor components [2]. In this test, pelargonidin was the highest anthocyanidin found in both strawberry cultivars, with Camarosa concentrations being the highest $(p \leq 0.05)$. Pelargonidin content in both Argentinian strawberry cultivars (Table 2) were found to be approximately in the same range as those obtained by Giné Bordonaba et al. [22] who reported pelargonidin-3-glucoside concentrations from 25.4 to $40.4 \mathrm{mg} / 100 \mathrm{~g}$ in three strawberry cultivars (Antea, Clery and Matis) from Switzerland. Cyanidin concentrations obtained in this study were slightly higher than values reported by the aforementioned authors (cyanidin-3-glucoside ranged from 1.3 to $1.4 \mathrm{mg} / 100 \mathrm{~g}$ ). Moreover, cyanidin concentration in Selva strawberries was higher than the value in Camarosa cultivar (Table 2). Total anthocyanidin contents (pelargonidin plus cyanidin) were 29.7 and $24.0 \mathrm{mg} / 100 \mathrm{~g} \mathrm{FW}$ for Camarosa and Selva, respectively; which represent $48.8 \%$ and $39.8 \%$ of the sum of all phenolic compounds, respectively (Table 2). Our results were in agreement with Castro et al. [23] who analyzed the total anthocyanin content in Selva and Camarosa strawberries from Portugal and Spain, respectively. Authors reported that the total anthocyanin concentration in Camarosa was higher than in Selva. 
Total phenolics content was measured by the Folin-Ciocalteu method and the sum of each phenolic compound analyzed by HPLC-DAD in both strawberry cultivars. Results were different for both methodologies (Tables 1 and 2). As can be seen, total phenolics analyzed by Folin-Ciocalteu assay were higher than those obtained as the sum of phenolic compounds obtained by HPLC-DAD. It is known that Folin-Ciocalteu assay suffers from a number of interfering substances (particularly sugars, aromatic amines, sulfur dioxide, ascorbic acid, organic acid, and Fe (II)) which may also react with the reagent to give greater apparent phenolic concentrations [24]. Total phenolics content was $10 \%$ higher in Camarosa cultivar by the Folin-Ciocalteu method, and did not present differences between cultivars when it was calculated as the sum of phenolic compounds assayed by HPLC-DAD.

\subsection{Antioxidant Capacity}

The antioxidant activities for both methods in the cultivars are shown in Table 1. Results were in agreement with those reported by Halvonsen et al. [25] for three cultivars from Norway (ranging from 1.85 to $2.34 \mathrm{mmol} \mathrm{Fe}{ }^{2+} / 100 \mathrm{~g} \mathrm{FW}$ ) and Leong and Shui [26], who reported a total antioxidant capacity of approximately $500 \mathrm{mg} \mathrm{AA} / 100 \mathrm{~g} \mathrm{FW}$ in strawberries from Singapore. The antioxidant capacity in Camarosa was higher than in Selva strawberries $(p \leq 0.05)$. The anthocyanins and the ellagitannins are the groups with highest contributions to total antioxidant capacity in strawberries, while it was estimated that vitamin $\mathrm{C}$ contributes $15 \%$ to $30 \%$ to this capacity $[4,16]$. The higher antioxidant capacity determined in Camarosa strawberries was in accordance with the higher anthocyanin content observed for these berries. However, Selva strawberries presented higher ellagic acid content (Table 2), which leads to a good level of antioxidant capacity in this cultivar. Since the strawberries used for this study come from different origins, it could also be possible that the differences found could be due to different culture conditions and not so much to the genetics of the cultivar.

\section{Conclusions}

The study of two strawberry cultivars from Argentina (Camarosa and Selva) indicated that there were differences in the bioactive compounds content and antioxidant capacity, but both were in the range of other varieties from others countries. The Camarosa cultivar presented higher total phenolic and anthocyanins content, and presented consequently a better antioxidant capacity for DPPH* and FRAP assays. However, the vitamin $\mathrm{C}$ content for both cultivars was in the same range. The results indicated that Camarosa strawberries, which are the most cultivated, consumed, and exported berries in Argentina, presented suitable bioactive compound levels with beneficial effects for human health. Moreover, the research points out that the strawberry varieties from Argentina are an interesting source of bioactive compounds comparable to those in other parts of the world.

\section{Acknowledgments}

Authors acknowledge to Universidad Nacional del Litoral (Argentina) for financial support through project CAI+D 2009. Franco Van de Velde was supported with a doctoral grant, from CONICET, Argentina and with an internship grant from IILA (Instituto Italolatinoamericano). 


\section{Conflict of Interest}

The authors declare no conflict of interest.

\section{References}

1. Cordenunsi, B.R.; Genovese, M.I.; Oliveira do Nascimento, J.R.; Hassimotto, N.M.A.; dos Santos, R.J.; Lajolo, F.M. Effects of temperature on the chemical composition and antioxidant activity of three strawberry cultivars. Food Chem. 2005, 91, 113-121.

2. Da Silva Pinto, M.; Lajolo, F.; Genovese, M. Bioactive compounds and quantification of ellagic acid in strawberries (Fragaria x ananassa Duch.). Food Chem. 2008, 107, 1629-1635.

3. Giampieri, F.; Tulipani, S.; Alvarez-Suarez, A.M.; Quiles, J.L.; Mezzetti, B.; Battino, M. The strawberry: Composition, nutritional quality, and impact on human health. Nutrition 2012, 28, 9-19.

4. Lopes Da Silva, F.; Escribano-Bailón, M.; Pérez Alonso, J.; Rivas-Gonzalo, J.C.; Santos-Buelga, C. Anthocyanin pigments in strawberry. LWT Food Sci. Technol. 2007, 40, 374-382.

5. Molina, N.; Giménez, L.; Richieri, C. Horticultural Sector Economy of Corrientes. Regional Strawberry Production and Its Relationship to the National Supply and MERCOSUR, 2007 (in Spanish). Available online: http://inta.gob.ar/documentos/economia-del-sector-horticola-decorrientes.-produccion-frutillera-regional-y-su-relacion-con-la-oferta-nacional-y-del-mercosur (acceded on 14 March 2013).

6. Saccone, K. Characterization of Coronda Area as a Producer of Strawberries. Secretary for Production and Environment, Municipality of Coronda, Santa Fe, Argentina, 2006 (in Spainsh). Available online: http://64.76.123.202/SAGPYA/economias_regionales/_frutas/_informes/ Produccion_de_frutillas_en_coronda.pdf (acceded on 14 March 2013).

7. Deutsch, M.J. Official Methods of Analysis; Association of Official Agricultural Chemists International: Arlington, VA, USA, 1995.

8. Van De Velde, F.; Pirovani, M.E.; Cámara, M.S.; Güemes, D.R.; Bernardi, C. Optimization and validation of a UV-HPLC method for vitamin $\mathrm{C}$ determination in strawberries (Fragaria ananassa Duch.), using experimental designs. Food Anal. Methods 2012, 5, 1097-1104.

9. Tarola, A.M.; van de Velde, F.; Salvagni, L.; Pretti, R. Determination of phenolic compounds in strawberries (Fragaria ananassa Duch) by high performance liquid chromatography with diode array detection. Food Anal. Methods 2013, 6, 227-237.

10. Jin-Heo, H.; Yong-Lee, C. Strawberry and its anthocyanins reduce oxidative stress-induced apoptosis in PC12 cells. J. Agric. Food Chem. 2005, 53, 1984-1989.

11. Singleton, V.L.; Rossi, J.A. Colorimetry of total phenolics with phosphomolybdic-phosphotungstic acid reagents. Am. J. Enol. Vitic. 1965, 16, 144-158.

12. Sánchez-Moreno, C.; Plaza, L.; de Ancos, B.; Cano, M.P. Quantitative bioactive compounds assessment and their relative contribution to the antioxidant capacity of commercial orange juices. J. Sci. Food Agric. 2003, 83, 430-439. 
13. Lim, Y.Y.; Lim, T.T.; Tee, J.J. Antioxidant properties of several tropical fruits: A comparative study. Food Chem. 2007, 103, 1003-1008.

14. Benzie, I.F.F.; Strain, J.J. Simultaneous automated measurement of the total antioxidant (reducing) capacity and ascorbic acid concentration. Redox. Rep. 1997, 3, 233-238.

15. Tulipani, S.; Mezzetti, B.; Capocasa, F.; Bompadre, S.; Beekwilder, J.; Ric de Vos, C.H.; Capanoglu, E.; Bovy, A.; Battino, M. Antioxidants, phenolic compounds, and nutritional quality of different strawberry genotypes. J. Agric. Food Chem. 2008, 56, 696-704.

16. Pincemail, J.; Kevers, C.; Tabart, J.; Defraigne, J.O.; Dommes, J. Cultivars, culture conditions, and harvest time influence phenolic and ascorbic acid contents and antioxidant capacity of strawberry (Fragaria x ananassa). J. Food Sci. 2012, 77, 205-210.

17. Davey, M.W.; van Montagu, M.; Inzé, D.; Sanmartin, M.; Kanellis, A.; Smirnoff, N.; Benzie I.J.J.; Strain J.J.; Favell, D.; Fletcher, J. Review: Plant L-ascorbic acid: chemistry, function, metabolism, bioavailability and effects of processing. J. Sci. Food Agric. 2000, 80, 825-860.

18. Häkkinen, S.; Törrönen, A. Content of flavonols and selected phenolic acids in strawberries and Vaccinium species: Infuence of cultivar, cultivation site and technique. Food Res. Int. 2000, 33, 517-524.

19. Mattila, P.; Kumpulainen, J. Determination of free and total phenolic acids in plant-derived foods by HPLC with diode-array detection. J. Agric. Food Chem. 2002, 50, 3660-3667.

20. Baettie, J.; Crozier, A.; Duthie, G.G. Potential health benefits of berries. Curr. Nutr. Food Sci. 2005, 1, 71-86.

21. Williner, M.R.; Pirovani, M.E.; Güemes, D.R. Ellagic acid content in strawberries of different cultivars and ripening stages. J. Sci. Food Agric. 2003, 83, 842-845.

22. Giné Bordonaba, J.; Crespo, P.; Terry, L. A new acetonitrile-free mobile phase for HPLC-DAD determination of individual anthocyanins in blackcurrant and strawberry fruits: A comparison and validation study. Food Chem. 2011, 129, 1265-1273.

23. Castro, I.; Gonçalves, J.A.; Vicente, A.A. Comparative study of Selva and Camarosa strawberries for the comercial market. J. Food Sci. 2002, 67, 2132-2136.

24. Prior, R.L.; Wu, X.; Schaich, K. Standardized methods for the determination of antioxidant capacity and phenolics in food and dietary supplements. J. Agric. Food Chem. 2005, 5, 4290-4302.

25. Halvorsen, B.L.; Holte, K.; Myhrstad, M.C.W.; Barikmo, I.; Hvattum, E.; Remberg, S.F.; Wold, A.B.; Haffner, K.; Baugerød, H.; Andersen, L.F.; et al. A systematic screening of total antioxidants in dietary plants. J. Nutr. 2002, 132, 461-471.

26. Leong, L.P.; Shui, G. An investigation of antioxidant capacity of fruits in Singapore markets. Food Chem. 2007, 79, 69-75.

(C) 2013 by the authors; licensee MDPI, Basel, Switzerland. This article is an open access article distributed under the terms and conditions of the Creative Commons Attribution license (http://creativecommons.org/licenses/by/3.0/). 